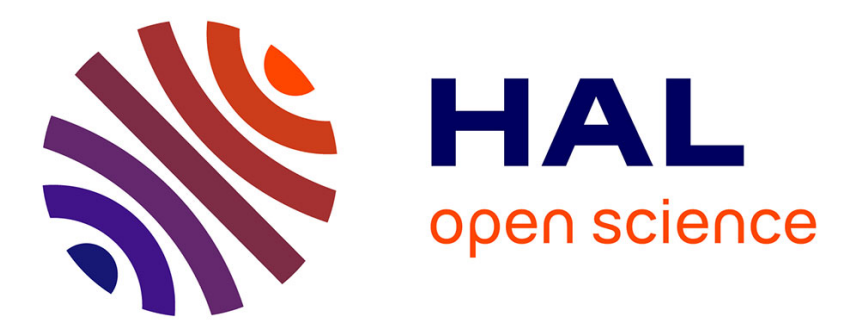

\title{
Efficient laser operation of an Yb:S-FAP crystal at 985 nm
}

Sylvie Yiou, François Balembois, Kathleen Schaffers, Patrick Georges

\section{To cite this version:}

Sylvie Yiou, François Balembois, Kathleen Schaffers, Patrick Georges. Efficient laser operation of an Yb:S-FAP crystal at $985 \mathrm{~nm}$. Applied optics, 2003, 42 (24), pp.4883-4886. hal-00701618

\section{HAL Id: hal-00701618 \\ https://hal-iogs.archives-ouvertes.fr/hal-00701618}

Submitted on 25 May 2012

HAL is a multi-disciplinary open access archive for the deposit and dissemination of scientific research documents, whether they are published or not. The documents may come from teaching and research institutions in France or abroad, or from public or private research centers.
L'archive ouverte pluridisciplinaire HAL, est destinée au dépôt et à la diffusion de documents scientifiques de niveau recherche, publiés ou non, émanant des établissements d'enseignement et de recherche français ou étrangers, des laboratoires publics ou privés. 


\title{
Efficient laser operation of an Yb:S-FAP crystal at $985 \mathrm{~nm}$
}

\author{
Sylvie Yiou, François Balembois, Kathleen Schaffers, and Patrick Georges
}

\begin{abstract}
We have obtained three-level cw laser operation at $985 \mathrm{~nm}$ with a $\mathrm{Yb}$-doped S-FAP bulk crystal pumped by a Ti:sapphire laser. An output power of $250 \mathrm{~mW}$ for an incident pump power of $1.45 \mathrm{~W}$ has been achieved, which is the highest cw output power ever obtained, to our knowledge, at this wavelength with a Yb-doped crystal. The experimental results are in good agreement with the numerical model that we have developed. (C) 2003 Optical Society of America

OCIS codes: $140.3580,160.5690$.
\end{abstract}

\section{Introduction}

As the number of optical channels in the telecommunications area increases, there is a strong need for the development of new laser sources that emit an output power of a few watts around $985 \mathrm{~nm}$ with a good beam quality for the pumping of erbiumdoped fiber amplifiers. Several ways have already been successfully studied, such as the development of novel semiconductor-based laser devices (for example, the extended-cavity surface-emitting laser, ${ }^{1}$ the $\alpha$-distributed-feedback laser, ${ }^{2}$ or the optically pumped semiconductor ${ }^{3}$ ) or semiconductor laser diodes in external cavities. ${ }^{4}$ Another solution to get a compact laser source emitting around $985 \mathrm{~nm}$ is to use ytterbium-doped (Yb-doped) materials. Depending on the host material, the Yb-doping ion can present a relatively large absorption band around $900 \mathrm{~nm}$ useful for diode pumping and a laser transition around $980 \mathrm{~nm} \cdot{ }^{5}$ However, this is a true three-level laser transition, which implies a high pump power density to invert half of the total population density and to overcome the absorption at the laser wavelength. Moreover, a well-known laser oscillation around $1010-1050 \mathrm{~nm}$ is more favor-

S. Yiou (sylvie.yiou@iota.u-psud.fr), F. Balembois, and P. Georges are with the Laboratoire Charles Fabry de l'Institut d'Optique, Unité Mixte de Recherche 8501 du Centre National de la Recheche Scientifique, Centre Universitaire Paris XI, Bâtiment 503, 91403 Orsay, France. K. Schaffers is with the Lawrence Livermore National Laboratory, 7000 East Avenue, L-482, Livermore, California 94551.

Received 21 January 2003; revised manuscript received 30 April 2003.

0003-6935/03/244883-04\$15.00/0

(C) 2003 Optical Society of America able than the transition around $980 \mathrm{~nm}$ and is to be suppressed. Efficient operation of a Yb-doped silica-fiber laser around $980 \mathrm{~nm}$ has been obtained, ${ }^{6}$ thanks to the possibility of achieving both extremely high pump intensities with a small core fiber and a good overlapping between the pump and the laser beams. In contrast, laser operation of a three-level Yb-doped bulk crystal around $980 \mathrm{~nm}$ is much more challenging because the pump-intensity requirements are so high that the oscillation threshold cannot generally be reached with pump sources of a few watts. The only $\mathrm{Yb}$-doped crystal lasers at $985 \mathrm{~nm}$ reported in the literature are a long-pulse-pumping quasi-cw Yb:S-FAP laser ${ }^{7}$ and a Ti:Sapphire-pumped $\mathrm{cw} \mathrm{Yb}_{\mathrm{C}} \mathrm{SFAP}$ with a low slope efficiency (5\%) and a high laser threshold (516 $\mathrm{mW}){ }^{8}$ The aim of the present paper is to report efficient $\mathrm{cw}$ three-level laser operation at $985 \mathrm{~nm}$ with an Ylo-doped bulk crystal. We introduce a selection criterion for the host material. Then we describe the experimental setup and expose the results obtained with the crystal selected as well as comparisons with our numerical model.

\section{Choice of the Crystal}

Many crystals have been reported in the literature to serve as host materials for Yb. As the laser threshold is difficult to achieve in three-level lasers, we have chosen the pump intensity $I_{p}$ necessary to reach transparency as a selection criterion for the host material. $I_{p}$ is the pump intensity (in kilowatts per square centimeter) above which the gain coefficient $g=\sigma_{\mathrm{el}} N_{2}-\sigma_{\mathrm{al}} N_{1}$ is positive, with $N_{2}$ and $N_{1}$ as the population densities of the upper and lower manifolds, respectively, $\sigma_{\text {al }}$ as the effective absorption cross section at the laser wavelength, and $\sigma_{\mathrm{el}}$ as the 
Table 1. Estimation of the Transparency Pump Intensity $I_{p}$ for Different Yb-Doped Materials ${ }^{a}$

\begin{tabular}{|c|c|c|c|c|c|c|c|}
\hline Host Material & $\lambda_{p}(\mathrm{~nm})$ & $\lambda_{l}(\mathrm{~nm})$ & $\begin{array}{c}\sigma_{\mathrm{al}} \\
\left(10^{-20} \mathrm{~cm}^{2}\right)\end{array}$ & $\begin{array}{c}\sigma_{\mathrm{ap}} \\
\left(10^{-20} \mathrm{~cm}^{2}\right)\end{array}$ & $\begin{array}{c}\sigma_{\mathrm{el}} \\
\left(10^{-20} \mathrm{~cm}^{2}\right)\end{array}$ & $\begin{array}{c}\tau \\
(\mathrm{ms})\end{array}$ & $\begin{array}{c}I_{p} \\
\left(\mathrm{~kW} / \mathrm{cm}^{2}\right)\end{array}$ \\
\hline GdCOB $^{9}$ & 900 & 976 & 1.2 & 0.5 & 0.5 & 2.74 & 38 \\
\hline $\mathrm{LiYO}_{2}{ }^{5}$ & 908 & 972 & 0.8 & 1.2 & 0.5 & 1.13 & 26 \\
\hline YAG $^{10}$ & 941 & 968 & 0.75 & 0.77 & 1 & 0.95 & 22 \\
\hline Tungstate (KGW) ${ }^{11}$ & $935(E \| a)$ & $981(E \| a)$ & 12 & 2.5 & 16 & 0.6 & 10 \\
\hline Apatite (S-FAP) ${ }^{12,13}$ & $900(E \| c)$ & $985(\mathrm{E} \perp c)$ & 10 & 9 & 10 & 1.14 & 2 \\
\hline
\end{tabular}

${ }^{a} \sigma_{\mathrm{ep}}$ is negligible for these materials. $\lambda_{l}$ is the laser wavelength.

effective emission cross section at the laser wavelength. When there is no laser intensity in the cavity, the gain coefficient $g$ can also be written $a^{9}$

$$
g=N \frac{\left(\sigma_{\mathrm{el}} \sigma_{\mathrm{ap}}-\sigma_{\mathrm{al}} \sigma_{\mathrm{ep}}\right) \frac{\lambda_{p}}{h c} I_{p}-\frac{\sigma_{\mathrm{al}}}{\tau},}{\left(\sigma_{\mathrm{ap}}+\sigma_{\mathrm{ep}}\right) \frac{\lambda_{p}}{h c} I_{p}+\frac{1}{\tau}},
$$

with $\sigma_{\mathrm{ep}}$ as the effective emission cross section at the pump wavelength, $\sigma_{\text {ap }}$ as the effective absorption cross section at the pump wavelength, $\tau$ as the fluorescence lifetime, and $\lambda_{p}$ as the pump wavelength.

So $I_{p}$ is given by

$$
I_{p}=\frac{h c \sigma_{\mathrm{al}}}{\left(\sigma_{\mathrm{el}} \sigma_{\mathrm{ap}}-\sigma_{\mathrm{al}} \sigma_{\mathrm{ep}}\right) \tau \lambda_{p}} .
$$

On Table 1 we have reported $I_{p}$ for several host materials. Note that the intrinsic lifetime, i.e., the fluorescence lifetime without the effect of radiation trapping, is reported for only a few Yb-doped crystals (Yb:YAG, ${ }^{10} \mathrm{Yb}: \mathrm{S}-\mathrm{FAP},{ }^{11}$ and $\mathrm{Yb}: \mathrm{KYW}^{14}$ ). Moreover, a complete set of spectroscopic parameters (comprising intrinsic lifetime and cross sections at the pump wavelength around $900 \mathrm{~nm}$ and at the laser wavelength around $980 \mathrm{~nm}$ ) was reported only for $\mathrm{Yb}$ : YAG $^{10}$ and Yb:S-FAP. ${ }^{12,13}$ For the other crystals mentioned in Table 1, we used the fluorescence lifetimes given in the literature, which may be overestimated with respect to the intrinsic lifetimes. ${ }^{10}$ Nevertheless, the order of magnitude of $I_{p}$ should not be affected.

As evidenced by Table 1, the apatite structure appears to be the most favorable crystal host, owing to its high cross sections. In the apatite family the laser and spectroscopic properties of $\mathrm{Yb}$-doped $\mathrm{Sr}_{5}\left(\mathrm{PO}_{4}\right)_{3} \mathrm{~F}$ or S-FAP are among the most studied in the literature.7,8,12,13 Moreover, Yb:S-FAP has already been shown to be an ideal laser material in diode-pumped solid-state laser oscillator systems. ${ }^{15,16}$ So we have chosen to use Yb:S-FAP to demonstrate efficient cw three-level laser operation at $985 \mathrm{~nm}$.

\section{Experimental Setup}

Figure 1 shows the experimental setup. The laser rod is a 4-mm-long cube. The crystal is antireflection coated at 900 and $985 \mathrm{~nm}$ on both faces. The $\mathrm{Yb}$ concentration is $1.9 \times 10^{19}$ ions $/ \mathrm{cm}^{3}$. The crystal is end pumped along the $E \| c$ axis, and lasing at $985 \mathrm{~nm}$ will be preferentially along the $E \perp c$ axis. We have used a Ti:Sapphire laser emitting a maximum output power of $1.45 \mathrm{~W}$ at $900 \mathrm{~nm}$ in a nearly $\mathrm{TEM}_{00}$ beam to demonstrate the possibility of achieving cw operation at $985 \mathrm{~nm}$ with an Yb:S-FAP crystal. The pump beam is focused inside the laser rod by a 100 -mm focal-length lens, and the pump-beam-waist size radius in the crystal is measured to be approximately $80 \mu \mathrm{m}$. We have used a nearly concentric cavity with mirrors having a curvature radius of 100 $\mathrm{mm}$. This provides a laser-mode waist size in the crystal of approximately $40 \mu \mathrm{m}$. The three-level nature of the transition requires the laser mode in the gain medium to be highly overlapped by the pump beam. The input mirror (Laseroptik $\mathrm{GmbH}$ ) is highly transmissive at $900 \mathrm{~nm}$ and highly reflective at $985 \mathrm{~nm}$. The output mirror (VLOC) is highly reflective at $900 \mathrm{~nm}$ in order to recycle the pump laser beam. Moreover, both input and output mirrors are highly transmissive around $1047 \mathrm{~nm}$ to suppress laser oscillation on this transition. The transmission of the output coupler is $7 \%$ at $985 \mathrm{~nm}$.

\section{Laser Operation}

Lasing action is easily obtained at $985 \mathrm{~nm}$ with no parasitical laser oscillation at $1047 \mathrm{~nm}$. We have obtained an output power of $250 \mathrm{~mW}$ at $985 \mathrm{~nm}$ in a $\mathrm{TEM}_{00}$ laser beam for an incident pump power of 1.45 W. Laser threshold is reached for an incident pump power of $200 \mathrm{~mW}$. The slope efficiency with respect to the incident pump power is $20 \%$. We have reported the output power at $985 \mathrm{~nm}$ versus the incident pump power on Fig. 2 as well as a picture of the spatial profile of the laser beam to illustrate its good quality. We have also plotted the theoretical output power versus the incident pump power predicted by our numerical model. This model is inspired from the one described in Ref. 9. To take into account the

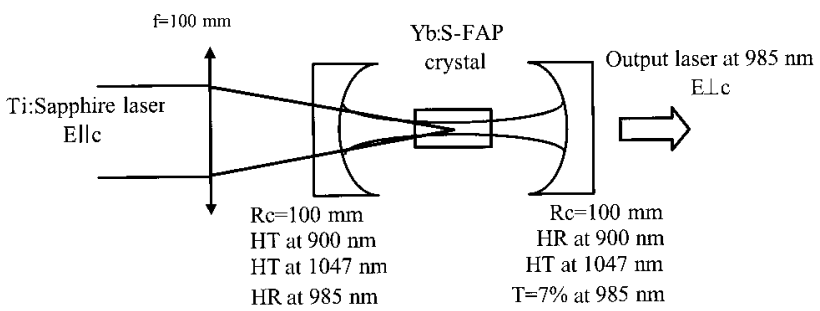

Fig. 1. Experimental setup. Rc, curvature radius; HT, highly transmissive, HR, highly reflective. 


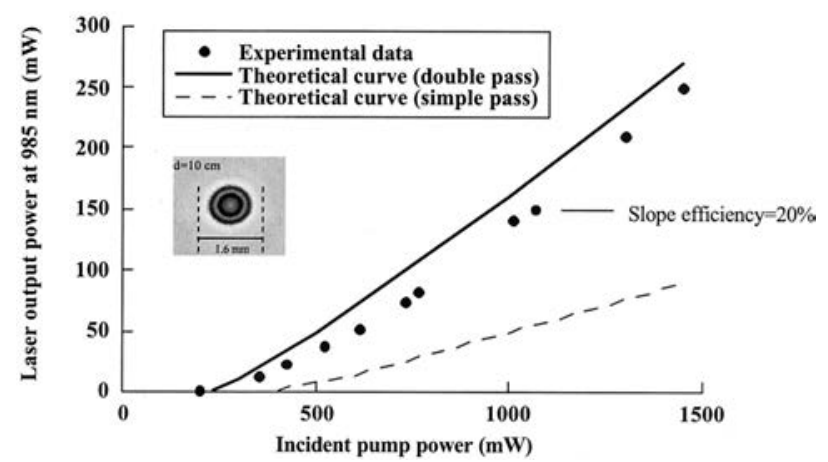

Fig. 2. Experimental (circles) and theoretical output power at 985 nm with (solid curve) and without (dashed curve) recycling of the pump versus incident pump power at $900 \mathrm{~nm}$ for an output coupler of $7 \%$. Picture of the spatial profile of the laser beam at a distance $d=10 \mathrm{~cm}$ from the crystal. The size of the beam diameter at $1 / e^{2}$ is $1.6 \mathrm{~mm}$ in both horizontal and vertical directions.

true three-level nature of the laser, our model calculates the small-signal gain per double pass integrated over the whole crystal without neglecting the saturation of absorption. Moreover, we have added the recycling of the pump in the expression of the smallsignal gain. The adjustable parameter is the double-pass passive losses, which were estimated to be approximately $5 \%$. Figure 2 shows that our experimental data are in good agreement with this numerical model. On Fig. 2 we have also plotted the theoretical output power versus the incident pump power without the recycling of the pump. This shows that the recycling of the pump increased the slope efficiency by a factor of 2.8 .

\section{Small-Signal Gain Measurements}

We also measured the small-signal gain as it is an important parameter for a laser medium. These small-signal gain measurements were carried out by varying the losses in the cavity with the use of different output couplers or the insertion of glass plates or both. On Fig. 3 we have plotted the theoretical small-signal gain with and without the recycling of the pump as well as the experimental small-signal

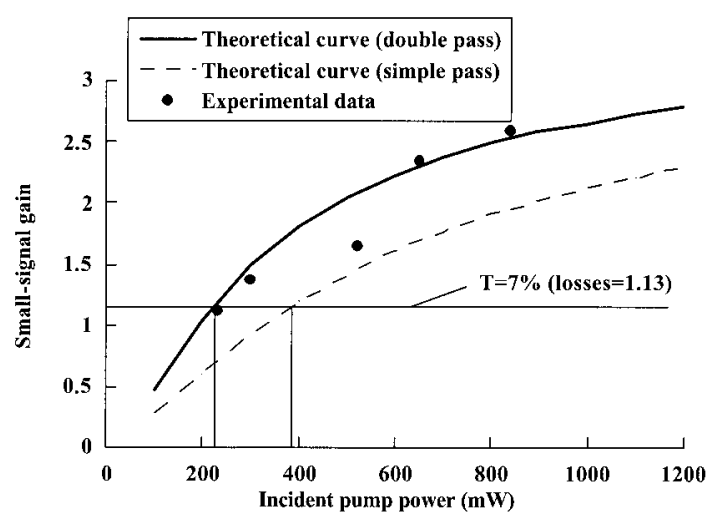

Fig. 3. Experimental (circles) and theoretical small-signal gain with (solid curve) and without (dashed curve) recycling of the pump versus incident pump power.

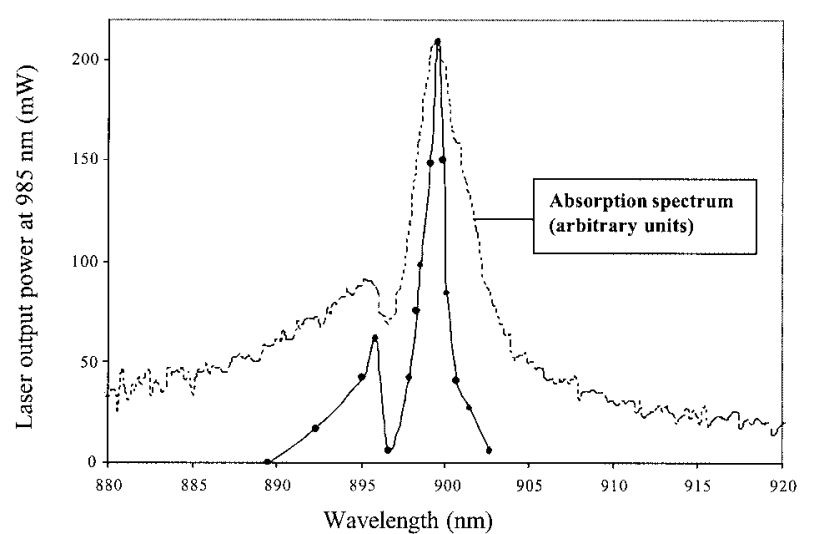

Fig. 4. Output power at $985 \mathrm{~nm}$ versus the wavelength of the pump Ti:Sapphire laser for anincident pump power of $1.45 \mathrm{~W}$ (bold curve). Comparison with the absorption spectrum of the Yb:SFAP in arbitrary units (dashed curve).

gain versus the pump power. As evidenced by Fig. 3 , the recycling of the pump permitted a decrease in the laser threshold pump power by a factor of 1.8 (the intersection between the gain curves and the loss curve gives the incident pump power at threshold). Actually, the saturated absorption of the pump on one pass was quite low (approximately 20\%), and the double pass of the pump provided a more efficient population inversion along the whole crystal. In this configuration the theoretical small-signal gain is as high as 2.8 for maximum available pump power. Experimentally, we have reached laser threshold with an equivalent output coupler of $61 \%$, corresponding to a small-signal gain of 2.62. This is a relatively high small-signal gain for a solid-state laser, allowing the introduction of quite important losses in the cavity. Moreover, such a crystal could be also useful for amplification. Figure 3 shows that the experimental results are in good agreement with the predictions of our model.

\section{Discussion on Diode Pumping}

As the ultimate aim of this laser is to be diode pumped, it is interesting to evaluate the pump spectral bandwidth that can lead to laser oscillation at $985 \mathrm{~nm}$. On Fig. 4 we have plotted the output power at $985 \mathrm{~nm}$ versus the wavelength of the Ti:Sapphire pump laser $\lambda_{p}$ for an incident pump power of $1.45 \mathrm{~W}$. Laser oscillation occurs from $\lambda_{p}=889.5 \mathrm{~nm}$ to $\lambda_{p}=$ $902.7 \mathrm{~nm}$, and the full width at half-maximum of the main peak is approximately $1.8 \mathrm{~nm}$, in the same range as the spectrum of laser diodes emitting an output power of $2 \mathrm{~W}$ with an emitting surface area of $1 \times 100 \mu \mathrm{m}$. Moreover, we have adapted our numerical model to diode pumping by taking into account the higher size of the pump beam at the focused point and the degradation of the diode pump beam in the slow axis direction with a beam-propagation factor $M^{2}$ of 15 . This has shown that laser operation could also be achievable with the kind of diode mentioned above. As shown on Fig. 5, our model predicted that the slope efficiency would be reduced by a 


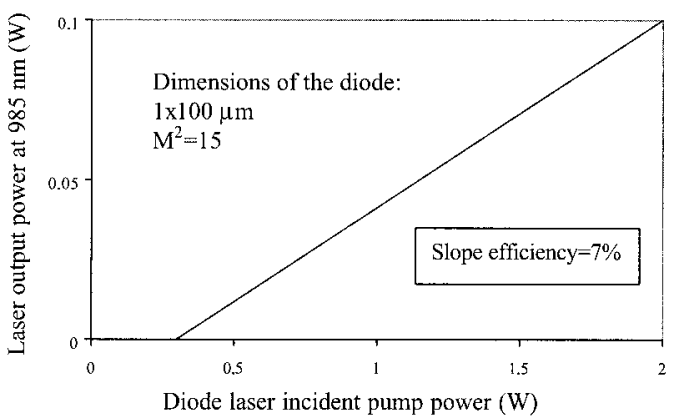

Fig. 5. Predictions of the output power versus incident pump power from our numerical model adapted to the diode pumping.

factor of 3 and the laser threshold would be raised to $300 \mathrm{~mW}$ of incident pump power. An output power of $100 \mathrm{~mW}$ at $985 \mathrm{~nm}$ would be obtained at the maximum pump power of $2 \mathrm{~W}$. These preliminary results are promising for the diode pumping of $\mathrm{Yb}$ : S-FAP crystals at $900 \mathrm{~nm}$.

\section{Conclusion}

In conclusion, the evaluation of the pump intensity at threshold for different crystals has led us to use an $\mathrm{Yb}: \mathrm{S}-\mathrm{FAP}$ crystal to achieve efficient $\mathrm{cw}$ three-level laser operation at $985 \mathrm{~nm}$. An output power of 250 $\mathrm{mW}$ has been obtained for an incident pump power of $1.45 \mathrm{~W}$, and laser threshold has been reached for an incident pump power of $200 \mathrm{~mW}$, leading to a slope efficiency with respect to the incident pump power of $20 \%$. This is, to our best knowledge, the highest cw output power ever obtained with an $\mathrm{Yb}$-doped crystal at this wavelength. This demonstration with a Ti: Sapphire laser is the first step to the diode pumping of an Yb:S-FAP crystal at $900 \mathrm{~nm}$ for cw laser emission at $985 \mathrm{~nm}$.

We thank the Laboratoire de Chimie Appliquée de l'Etat Solide of the Ecole Nationale Supérieure de Chimie Paris for the loan of its Ti:Sapphire laser as well as the NetTest company for the financial support of S. Yiou's Ph.D.

\section{References}

1. Novalux NXL-980MMP800 (Novalux extended-cavity surfaceemitting laser), Novalux, Inc., 1170 Sonora Court, Sunnyvale, Calif. 94086.

2. S. D. DeMars, K. M. Dzurko, R. J. Lang, D. F. Welch, D. R. Scifres, and A. Hardy, "Angled-grating distributed feedback laser with $1 \mathrm{~W}$ cw single-mode diffraction-limited output at 980 nm," in Conference on Lasers and Electro-Optics, Vol. 9 of 1996
OSA Technical Digest Series (Optical Society of America, Washington D.C., 1996), pp. 77-78.

3. M. Kuznetsov, F. Hakimi, R. Spragüe, and A. Mooradian, "High-power (5 W cw) diode-pumped vertical-external-cavity surface-emitting semiconductor lasers with circular $\mathrm{TEM}_{00}$ beams," IEEE Photon. Technol. Lett. 9, 1063-1065 (1997).

4. C. J. Chang-Hasnain, J. Berger, D. R. Scifres, W. Streifer, J. R. Whinnery, and A. Dienes, "High power with high efficiency in a narrow single-lobed beam from a diode laser array in an external cavity," Appl. Phys. Lett. 50, 1465-1467 (1987).

5. L. D. DeLoach, S. A. Payne, L. L. Chase, L. K. Smith, W. L. Kway, and W. F. Krupke, "Evaluation of absorption and emission properties of $\mathrm{Yb}^{3+}$ doped crystals for laser applications," IEEE J. Quantum Electron. 29, 1179-1190 (1993).

6. L. A. Zenteno, J. D. Minelly, A. Liu, A. J. G. Ellison, S. G. Crigler, D. T. Walton, D. V. Kuksenkov, and M. J. Dejneka, "1 $\mathrm{W}$ single-transverse-mode $\mathrm{Yb}$-doped double-clad fibre laser at 978 nm," Electron. Lett. 37, 819-820 (2001).

7. A. J. Bayramian, C. Bibeau, R. J. Beach, C. D. Marshall, S. A. Payne, and W. F. Krupke, "Three-level $Q$-switched laser operation of ytterbium-doped $\mathrm{Sr}_{5}\left(\mathrm{PO}_{4}\right)_{3} \mathrm{~F}$ at $985 \mathrm{~nm}$," Opt. Lett. 25, 622-624 (2000).

8. S. A. Payne, L. D. DeLoach, L. K. Smith, W. L. Kway, J. B. Tassano, and W. F. Krupke, B. H. T. Chai, and G. Loutts, "Ytterbium-doped apatite-structure crystals: a new class of laser materials," J. Appl. Phys. 76, 497-503 (1994).

9. F. Augé, F. Druon, F. Balembois, P. Georges, A. Brun, F. Mougel, G. Aka, and D. Vivien, "Theoretical and experimental investigations of a diode-pumped quasi-three-level laser: the $\mathrm{Yb}^{3+}$-doped $\mathrm{Ca}_{4}\left(\mathrm{GdO}\left(\mathrm{BO}_{3}\right)_{3}\right.$ ( $\left.\mathrm{Yb}: \mathrm{GdCOB}\right)$ laser," IEEE J. Quantum Electron. 36, 598-606 (2000).

10. D. S. Sumida and T. Y. Fan, "Effect of radiation trapping on fluorescence lifetime and emission cross section measurements in solid-state laser media," Opt. Lett. 19, 1343-1345 (1994).

11. N. V. Kuleshov, A. A. Podlipensky, and V. P. Mikhailov, "Pulsed laser operation of Yb-doped $\mathrm{KY}\left(\mathrm{WO}_{4}\right)_{2}$ and KGd $\left(\mathrm{WO}_{4}\right)_{2}$," Opt. Lett. 22, 1317-1319 (1997).

12. A. J. Bayramian, C. D. Marshall, K. I. Schaffers, and S. Payne, "Characterization of $\mathrm{Yb}^{3+}: \mathrm{Sr}_{5-x} \mathrm{Ba}_{x}\left(\mathrm{PO}_{4}\right)_{3} \mathrm{~F}$ crystals for diodepumped lasers," IEEE J. Quantum Electron. 35, 665-673 (1999).

13. L. D. DeLoach, S. A. Payne, L. K. Smith, W. L. Kway, and W. F. Krupke, "Laser and spectroscopic properties of $\mathrm{Sr}_{5}\left(\mathrm{PO}_{4}\right)_{3} \mathrm{~F}$ : Yb," J. Opt. Soc. Am. B 11, 269-275 (1994).

14. A. A. Demidovich, A. N. Kuzmin, G. I. Ryabtsev, M. B. Danailov, W. Strek, and A. N. Titov, "Influence of $\mathrm{Yb}$ concentration on Yb:KYW laser properties," J. Alloys Compd. 300-301, 238241 (2000).

15. C. D. Marshall, L. K. Smith, R. J. Beach, M. A. Emanuel, K. I. Schaffers, J. Skidmore, S. A. Payne, and B. H. T. Chai, "Diodepumped ytterbium-doped $\mathrm{Sr}_{5}\left(\mathrm{PO}_{4}\right)_{3} \mathrm{~F}$ laser performance," IEEE J. Quantum Electron. 32, 650-656 (1996).

16. M. R. Dickinson, L. A. W. Gloster, N. W. Hopps, and T. A. King, "Continuous-wave diode-pumped $\mathrm{Yb}^{3+}$ :S-FAP laser," Opt. Commun. 132, 275-278 (1996). 